\title{
Meeting report \\ It's all in the details: methods in breast development and cancer
} Mohamed Bentires-Alj ${ }^{1}$, Robert B Clarke ${ }^{2}$, Jos Jonkers ${ }^{3}$, Matthew Smalley ${ }^{4}$ and Torsten Stein ${ }^{5}$

\author{
${ }^{1}$ Friedrich Miescher Institute for Biomedical Research (FMI), Maulbeerstr. 66; CH-4058 Basel, Switzerland \\ ${ }^{2}$ Breast Biology Group School of Cancer and Imaging Sciences, Paterson Institute for Cancer Research, University of Manchester, Wilmslow Road, \\ Manchester M20 4BX, UK \\ ${ }^{3}$ Netherlands Cancer Institute; Division of Molecular Biology (P2), Plesmanlaan 121, 1066 CX Amsterdam, The Netherlands \\ ${ }^{4}$ Breakthrough Breast Cancer Centre, Institute of Cancer Research, 237 Fulham Road, London SW3 6JB, UK \\ ${ }^{5}$ Division of Cancer Sciences and Molecular Pathology, Section of Pathology and Gene Regulation, Western Infirmary, University of Glasgow, Glasgow \\ G11 6NT, UK
}

Corresponding author: Mohamed Bentires-Alj, Bentires@fmi.ch

Published: 14 August 2009

This article is online at http://breast-cancer-research.com/content/11/4/305

(c) 2009 BioMed Central Ltd
Breast Cancer Research 2009, 11:305 (doi:10.1186/bcr2346)

Dr Kim Jensen from Cambridge University. Robertson presented the latest developments in multi-colour fluorescent imaging using formalin-fixed paraffin-embedded (FFPE) sections. FFPE archives around the world add up to a large database of tumour samples, but standard staining using chromogenic substrates has several limitations, especially the inability to target multiple proteins simultaneously and the limited intracellular resolution. Immunofluorescence potentially provides increased resolution and allows a multi-colour approach. However, FFPE material often displays a high level of auto-fluorescence. Using an optimised protocol and confocal laser microscopy, Robertson was able to dramatically reduce this background fluorescence, allowing the use of four-colour fluorescence for cellular and intracellular colocalisation studies on FFPE tissue microarrays [1]. His latest protocols will be published on the ENBDC website [2].

Kim Jensen from Fiona Watt's laboratory also presented work on studying multiple genes in small samples. He has developed a technique for full genome microarray analysis on RNA amounts equivalent to that from a single cell using a PCR-based amplification step. This allowed him to study mRNA expression profiles of single flow sorted epidermal stem cells. In this way, Lrig1 was identified as a marker for epidermal stem cells that keeps these cells in a quiescent state [3]. Jensen further showed that Lrig1-positive cells define a distinct subpopulation in the hair follicle that can give rise to all epidermal cell lineages, as well as to cells of the sebaceous gland and the interfollicular epidermis [4]. This powerful technique thus allows the study of the expression profiles of very small numbers of cells, including from isolated cap cells of the mammary terminal end bud or from very small flow sorted mammary cell populations. 


\section{Cancer stem/progenitor cells of the breast (Chair: Rob Clarke)}

In the second session, Dr John Stingl from the Cancer Research UK Cambridge Research Institute spoke about the detection and analysis of mammary gland stem and progenitor cells. These cells are detected by their ability to generate ductal-lobular outgrowths when transplanted into immune-compatible mice and by their ability to generate colonies in vitro. Stingl reviewed some limitations of these assays, with particular emphasis on how variable they can be with minor changes in protocol. He presented results from his laboratory on how to minimize variability and increase the efficiency of these assays. For example, the enzymatic dissociation of mammary glands in growth factor-depleted versus growth factor-rich media results in the differential yield of mammary stem and progenitor cells, with stem cells preferring growth factor-depleted conditions and the progenitor cells favouring growth factor-rich conditions. As well, the detection frequency of stem cells can be increased approximately sixfold by the inclusion of Matrigel $^{\mathrm{TM}}$ within the transplant inoculum.

The second speaker, Dr Gabriela Dontu from King's College, University of London, talked about estrogen receptor (ER) expression in stem and progenitor cells from normal and malignant breast epithelium. Dontu proposed that no one stem cell marker is useful for all breast cancers and that there may be specific markers useful for different breast cancer subtypes, of which there are at least five. For example, aldehyde dehydrogenase expression determined by the fluorescent substrate Aldefluor is useful for enriching stem cells in normal and some malignant breast samples but is low in cell lines and absent in many ER-positive cancers [5]. Dontu argued that researchers should beware of several common misconceptions concerning cancer stem cells. In reality, there are unlikely to be universal markers, the cancer stem cell population may not be infrequent (up to $25 \%$ in melanoma) [6], there will be genetic and phenotypic heterogeneity within a tumour, not all tumours will be hierarchical, and the cancer stem cell model is compatible with, and not distinct from, the clonal evolution model.

\section{Animal models for studying breast cancer (Chair: Jos Jonkers)}

In the third session, Dr Sven Rottenberg from the Netherlands Cancer Institute talked about drug responses and therapy resistance in conditional mouse models of breast cancer. Resistance to chemotherapy is a central unsolved problem in breast cancer treatment, since most patients die of disseminated tumours that are resistant to all forms of therapy. To tackle clinically relevant mechanisms of drug resistance, Rottenburg used the K14cre;Brca1F/F;p53F/F mouse model for BRCA1-associated breast cancer [7], and found acquired resistance to cytotoxic drugs (doxorubicin, docetaxel) [8] and to the poly(ADP-ribose) polymerase (PARP) inhibitor AZD2281, which induces synthetic lethality in BRCA1-deficient tumours [9]. The only resistance mechanism identified thus far is upregulation of the P-glycoprotein multidrug efflux transporter. Although no resistance was observed for cisplatin, tumours could not be eradicated and consistently re-grew from small tumour remnants. These remnants were not enriched in tumour-initiating cells, but contained beta-galactosidase-positive and Ki-67-negative cells, suggesting (therapy-induced) senescence or dormancy as escape mechanisms.

The second speaker, Dr Vida Vafaizadeh from the GeorgSpeyer-Haus in Frankfurt am Main, Germany, investigated the role of Stat5 in mammary gland development and tumourigenesis via ex vivo transduction of primary mammary epithelial cells with lentiviral vectors encoding a Stat5specific short hairpin RNA (shStat5ab) or a constitutively active Stat5 variant (cS5F). The transduced mammary epithelial cells were transplantated into cleared fat pads to reconstitute functional glandular epithelium. Downregulation of Stat5 did not affect the outgrowth of primary ducts, but resulted in thinner ducts, reduced side-branching and impaired alveologenesis. Conversely, constitutive activation of Stat5 caused hyperproliferation of epithelial cells, thickening of the ducts and precocious alveolar development in nulliparous mice, indicating that Stat5 activity regulates the emergence of mature alveolar cells from luminal progenitors. The persistent activation of Stat5 during the involution stage prevents apoptosis of the epithelial cells and causes formation of tumours that also express activated Stat3.

\section{Studying normal mammary stem cells (Chairs: Matthew Smalley and Mohamed Bentires-Alj)}

In the final session, Dr Matthew Smalley from the Breakthrough Breast Cancer Research Centre discussed the preparation and flow cytometric analysis of primary mammary epithelial cells, including stem cells. His group uses the CD24, Sca1 and CD49f markers to isolate four lineages of the mammary gland: basal stem cells, basal myoepithelial cells, ER-positive luminal cells and ER-negative luminal cells [10]. The critical steps for optimal isolation of the different lineages and confirming the identity of the isolated subpopulations were the topics of Smalley's presentation. In particular, he focussed on the validation of antibodies used for flow cytometric cell separation. He argued that gating based on controls in which one antibody is left out of the staining cocktail ('fluorescence minus one' controls) are critical. He also noted that different fluorochromes conjugated to the same antibody clone may give different flow cytometric patterns, as may different clones against the same antigen. Hence, antibody titration to saturation must be carried out for each new fluorochrome combination. Finally, to assess the quality of the whole process, each population isolated must be characterised by testing expression of celltype specific markers and in vitro and in vivo functional assays $[10,11]$. 
The second speaker, Dr Marina Glukhova from the Institut Curie in Paris, discussed the usefulness of the keratin 5 (K5) promoter active in the basal cells from various stratified epithelia for targeting transgenes to the basal cell layer of the mammary epithelium. Glukhova's lab crossed transgenic mice expressing Cre recombinase under the control of the $\mathrm{K} 5$ promoter with mice presenting conditional alleles for $\beta 1$ integrin gene (itgb1F/F). In virgin mutant mice, $\beta 1$ integrin was efficiently deleted from the basal cell layer, whereas luminal cells remained $\beta 1$ integrin-positive. The deletion of the itgb1 gene completely abolished the regenerative potential of the mammary epithelium, suggesting that $\beta 1$ integrins are essential for the maintenance of the functional stem cell population [12]. Surprisingly, in pregnant mutant mice, luminal cells in the alveoli stained negative for $\beta 1$ integrin, suggesting that they originated from K5-positive basal cells. Further analysis showed that whereas wild-type basal cells divide parallel to the basement membrane and their progeny therefore remained in the basal layer, the orientation of basal division was random in glands from $\mathrm{K} 5 \mathrm{cre}$; /tg $\mathrm{b} 1 \mathrm{~F} / \mathrm{F}$ mice. This led to cell fate changes explaining the presence of progeny from the basal cells in the luminal layer. Further, using the $\mathrm{K} 5$ promoter, this lab has obtained transgenic mice presenting a constitutive activation of $\mathrm{Wnt} / \beta$-catenin signalling in basal mammary epithelial cells. These mice develop hyperplastic mammary lesions presenting characteristics similar to those of human breast basal-type carcinomas.

\section{Conclusion}

The meeting proved a very valuable forum for the dissemination of ideas and experiences relating to commonly used, but sometimes poorly understood, techniques in mammary cell biology. Talks by speakers from outside the mammary cell biology field also helped highlight, especially to younger researchers, potential new avenues for exploration. Planning is already beginning for the 2010 meeting, which, it is hoped, will prove as stimulating as in 2009.

\section{Competing interests}

The authors declare that they have no competing interests.

\section{Acknowledgements}

The ENDBC workshop was supported by the Breakthrough Breast Cancer, the Friedrich Miescher Institute for Biomedical Research (FMI) and the KGF (Kontaktgruppe für Forschungsfragen) member companies Roche, Novartis, and Merck Serono. MB-A thanks the Swiss Cancer League and the Novartis Research Foundation for support. RBC is a Breast Cancer Campaign-funded Senior Research Fellow. Work in MS laboratory is supported by Breakthrough Breast Cancer. MS also acknowledges support from the NIHR Biomedical Research Centre.

\section{References}

1. Robertson D, Savage K, Reis-Filho JS, Isacke CM: Multiple immunofluorescence labelling of formalin-fixed paraffinembedded (FFPE) tissue. BMC Cell Biol 2008, 9:13.

2. European Network of Breast Development and Cancer Labs [www.enbdc.org]

3. Jensen KB, Watt FM: Single-cell expression profiling of human epidermal stem and transit-amplifying cells: Lrig1 is a regula- tor of stem cell quiescence. Proc Natl Acad Sci USA 2006, 103:11958-11963.

4. Jensen KB, Collins CA, Nascimento E, Tan DW, Frye M, Itami S, Watt FM: Lrig1 expression defines a distinct multipotent stem cell population in mammalian epidermis. Cell Stem Cell 2009, 4:427-439.

5. Charafe-Jauffret E, Ginestier C, lovino F, Wicinski J, Cervera N, Finetti $\mathrm{P}$, Hur MH, Diebel ME, Monville F, Dutcher J, Brown M, Viens P, Xerri L, Bertucci F, Stassi G, Dontu G, Birnbaum D, Wicha MS: Breast cancer cell lines contain functional cancer stem cells with metastatic capacity and a distinct molecular signature. Cancer Res 2009, 69:1302-1313.

6. Quintana E, Shackleton M, Sabel MS, Fullen DR, Johnson TM, Morrison SJ: Efficient tumour formation by single human melanoma cells. Nature 2008, 456:593-598.

7. Liu X, Holstege $H$, van der Gulden $H$, Treur-Mulder M, Zevenhoven J, Velds A, Kerkhoven RM, van Vliet MH, Wessels LF, Peterse JL, Berns A, Jonkers J: Somatic loss of BRCA1 and p53 in mice induces mammary tumors with features of human BRCA1-mutated basal-like breast cancer. Proc Natl Acad Sci USA 2007, 104:12111-12116.

8. Rottenberg $S$, Nygren $A O$, Pajic $M$, van Leeuwen $F W$, van der Heijden I, van de Wetering K, Liu X, de Visser KE, Gilhuijs KG, van Tellingen O, Schouten JP, Jonkers J, Borst P: Selective induction of chemotherapy resistance of mammary tumors in a conditional mouse model for hereditary breast cancer. Proc Natl Acad Sci USA 2007, 104:12117-12122.

9. Rottenberg S, Jaspers JE, Kersbergen A, van der Burg E, Nygren AO, Zander SA, Derksen PW, de Bruin M, Zevenhoven J, Lau A, Boulter R, Cranston A, O'Connor MJ, Martin NM, Borst P, Jonkers $\mathrm{J}$ : High sensitivity of BRCA1-deficient mammary tumors to the PARP inhibitor AZD2281 alone and in combination with platinum drugs. Proc Natl Acad Sci USA 2008, 105:17079-17084.

10. Sleeman KE, Kendrick H, Robertson D, Isacke CM, Ashworth A, Smalley MJ: Dissociation of estrogen receptor expression and in vivo stem cell activity in the mammary gland. J Cell Biol 2007, 176:19-26.

11. Sleeman KE, Kendrick $H$, Ashworth $A$, Isacke CM, Smalley MJ: CD24 staining of mouse mammary gland cells defines luminal epithelial, myoepithelial/basal and non-epithelial cells. Breast Cancer Res 2006, 8:R7.

12. Taddei I, Deugnier MA, Faraldo MM, Petit V, Bouvard D, Medina D, Fassler R, Thiery JP, Glukhova MA: Beta1 integrin deletion from the basal compartment of the mammary epithelium affects stem cells. Nat Cell Biol 2008, 10:716-722. 